\title{
Reformas curriculares na educação básica sob três perspectivas: BNCC, mediações estaduais e experiências de ensino de música em escolas públicas
}

Curricular reforms in basic education under three perspectives: common national curricular basis

(BNCC), state mediations and music teaching experiences in public schools

Ronaldo Aparecido de Matos Universidade Estadual de Londrina (UEL) ronaldomatos@uel.br http://orcid.org/0000-0003-3372-0488

Sérgio Inácio Torres² Universidade Estadual de São Paulo - Instituto de Artes (UNESP-IA) sergio.torres@unesp.br 


\section{Resumo}

Este trabalho tem como finalidade discutir sobre as dificuldades dos professores de Música da Educação Básica diante das proposições de ensino presentes na Base Nacional Comum Curricular - BNCC (BRASIL, 2018). Iniciamos as argumentações do trabalho por uma análise crítica da BNCC, com enfoque nos direcionamentos e conteúdos da área de Arte, na qual a Música está integrada. Em seguida, propomos uma breve análise de como as instituições estaduais efetuam as mediações da base comum para contextos regionais específicos, a partir do Referencial Curricular Paranaense - RCP (PARANÁ, 2018). Por fim, apresentamos algumas possibilidades para lidar com as proposições curriculares em âmbito nacional (BNCC) e estadual (RCP) no ambiente escolar. Para isso, tomamos como base experiências de ensino e aprendizagem em Música oriundas de atividades de estágio obrigatório, que foram aplicadas em colégios públicos londrinenses em turmas dos anos finais do segundo ciclo do Ensino Fundamental. Por meio das análises e argumentações estabelecidas no decorrer do trabalho, esperamos contribuir para discussões futuras e ao desenvolvimento de novas estratégias de ensino, levando em consideração parâmetros curriculares que dialoguem com a realidade da escola pública e de seus professores e alunos, bem como da comunidade que as integra.

\section{Abstract}

This paper aims to discuss the difficulties of music teachers of Basic Education facing the teaching propositions present in the Common National Curricular Base - BNCC (BRASIL, 2018). We begin the arguments of the work by a critical analysis of the BNCC, focusing on the directions and contents of the Art area, in which Music is integrated. Then, we propose a brief analysis of how the state institutions make the mediations of the common base for specific regional contexts, from the Paranaense Curricular Reference - RCP (PARANÁ, 2018). Finally, we present some possibilities for dealing with the curricular propositions at national level (BNCC) and state (RCP) in the school environment. For this, we take as basis teaching and learning experiences in Music coming from mandatory internship activities, which were applied in public schools in London in classes of the final years of the second cycle of elementary education. Through the analysis and argumentation established during the work, we hope to contribute to future discussions and to the development of new teaching strategies, considering curricular parameters that dialogue with the reality of public schools and their teachers and students, as well as the community that integrates them.

Keywords: BNCC; Music teaching; Basic education

Palavras-chave: BNCC; Ensino de música; Educação básica.

\footnotetext{
1 Mestre em Etnomusicologia pela Universidade Estadual Paulista Júlio de Mesquita Filho (UNESP-IA, 2016). Graduado em Licenciatura em Música pela Universidade Estadual de Londrina (UEL, 2011). Atualmente, é docente do curso de Graduação em Música (Licenciatura) da UEL na área de Educação Musical.

2 Pianista e professor. Doutorando em Música (UNESP-IA), Mestre em Música (UFPR, 2011), Especialista em Arte-Educação (IBPEX, 2010) e Graduado em Música - Instrumento Piano (EMBAP, 2007) e em Teologia (CESUMAR, 2015).
} 


\section{Considerações preliminares}

Neste estudo vamos discutir a respeito das convergências e divergências das reformas curriculares na Educação Básica brasileira, oriundas da aprovação da Base Nacional Comum Curricular - BNCC, (BRASIL, 2018), e as consequências dessas reformulações para o ensino de Música. Para isso, discorremos sobre o tema proposto com base em três perspectivas: a do próprio documento que fomentou tais reformas curriculares, as mediações de adequação curricular estabelecidas pelo Estado do Paraná e os relatos de experiência de ensino de Música realizados em escolas públicas. Esses três pontos de vista trazem análises e reflexões sobre os desafios que os professores da Educação Básica podem enfrentar para estabelecer um ponto de contato entre os direcionamentos propostos pelos novos currículos e as práticas pedagógicas em Música na Educação Básica.

De antemão, é importante salientar a existência de outras perspectivas que integram esse tema, por exemplo, as mediações estabelecidas pelos municípios, os projetos político-pedagógicos das escolas e a própria percepção dos alunos e da comunidade a respeito dessas reformulações. Contudo, por escolha metodológica e pela natureza do trabalho, estes aspectos citados não serão abordados.

A elaboração de uma base comum para nortear os conteúdos curriculares da Educação Básica brasileira, de forma democrática e igualitária, já era uma ação prevista desde a Constituição de 1988 (BRASIL, 1988) e teve avanços consideráveis a partir de 1996, com a aprovação da Lei de Diretrizes e Bases da Educação Nacional (BRASIL, 1996). Porém, somente em 2014, por meio da criação do Plano Nacional de Educação (BRASIL, 2014), é que se concretizou a criação dessa base comum, denominada Base Nacional Comum Curricular, a BNCC.

Em vigor desde 2018, a BNCC é um documento de caráter normativo que define as aprendizagens essenciais que todos os alunos brasileiros devem desenvolver ao longo das etapas e modalidades da Educação Básica, de modo que tenham assegurados seus direitos de aprendizagem e desenvolvimento (BRASIL, 2018, p. 7). O documento traz um conjunto de orientações que servem de referência para as escolas públicas e privadas elaborarem suas propostas curriculares nos três ciclos da Educação Básica brasileira: Educação Infantil, Ensino Fundamental e Ensino Médio.

A concepção e a proposição de uma base comum curricular têm sido uma discussão presente desde o processo de elaboração prévia da BNCC, a partir de 2014, e envolvem as diversas áreas de conhecimento que integram os currículos escolares, como Educação Física (NEIRA, 2018), Língua Portuguesa (GONTIJO, 2015), História (MORENO, 2016), Matemática (LOPES, 2016) e Arte (PIMENTEL e MAGALHÃES, 2018; DOURADO e SIQUEIRA, 2019; BORTOLUCCI et al., 2020; FRANÇA, 2020). No caso desta última área, especificamente, além das demandas de análise e discussão das proposições da BNCC, há também aspectos presentes no documento que envolvem as especificidades das linguagens artísticas - artes visuais, dança, música e teatro - e as concepções de objetivos e habilidades aplicadas a cada uma delas.

Isto posto, é importante deixar claro que nossa intenção neste estudo não é a de analisar detalhada e integralmente o documento em questão, não apenas pela densi- 
dade e complexidade das concepções e proposições nele presentes, mas também pelo fato de que se trata de um conjunto de diretrizes que envolve diferentes ciclos da Educação Básica, cada um com características e particularidades que demandam análises e discussões específicas para cada uma dessas etapas. Portanto, dada a essa complexidade e amplitude, abordamos aspectos específicos do documento, com base na área de Linguagens, na qual a Música está inserida como área temática do componente curricular Arte. Além disso, tomamos como enfoque um ciclo etário em particular, no caso, os anos finais do segundo ciclo do Ensino Fundamental.

Outro ponto importante a ser ressaltado é o de que os processos de reformulação curricular propostos pela BNCC necessitam de mediações a serem estabelecidas por outras instituições públicas estaduais e municipais a fim de que cada uma dessas instâncias estabeleça seus próprios critérios curriculares, levando em consideração não só a BNCC, como também o contexto e as características de cada região. Para abordar esse aspecto, selecionamos dois documentos elaborados pelo Estado do Paraná para exemplificar essa tentativa de mediação entre diretrizes de âmbito nacional e estadual: Referencial Curricular do Paraná - RCP (PARANÁ, 2018) e Currículo da Rede Estadual Paranaense - CREP (PARANÁ, 2019a).

A partir desses documentos estaduais, elegemos pontos específicos sob os mesmos critérios de seleção e análise aplicados à BNCC, visando estabelecer um comparativo acerca dos mesmos aspectos entre essas duas instâncias, a nacional e a estadual. Assim, os critérios curriculares nacionais e estaduais são apresentados de modo preliminar, para, em seguida, dar margem à discussão sobre como os professores de Música têm lidado com esses direcionamentos curriculares propostos e sobre como isso tem refletido em suas práticas pedagógicas na educação básica pública.

Para isso, partimos de experiências de estágio curricular obrigatório do curso de Licenciatura em Música da Universidade Estadual de Londrina. São vivências de ensino de Música ocorridas em colégios da rede pública paranaense, na cidade de Londrina ${ }^{3}$, aplicadas em turmas de $9^{\circ}$ ano do segundo ciclo do Ensino Fundamental, durante o ano letivo de 2019, contexto e período em que as reformulações curriculares da BNCC já estavam em vigor. Almejamos que esses relatos de experiência, mesmo que resultantes de contextos escolares específicos, possam trazer para o campo do debate algumas convergências e divergências que a reformulação curricular proposta pela BNCC pode ocasionar, como também compartilhar algumas possibilidades pedagógicas diante dessas proposições curriculares.

Além disso, as análises e comparações estabelecidas entre os três níveis institucionais - nacional, estadual e escola pública local - podem contribuir para novas reflexões a respeito da BNCC, dos critérios curriculares das instituições de ensino e da própria aplicabilidade dessas proposições em sala de aula. Já a escolha metodológica deste trabalho se deu como uma pesquisa exploratória, tendo como propósito contribuir na formulação de um problema, no sentido de enunciar questões e hipóteses para inves-

3 Escola Estadual Kazuko Ohara e Escola Estadual Ana Molina Garcia. 
tigações subsequentes (COOPER e SCHINDLER, 2003). Quanto ao método, optou-se pela coleta de dados bibliográficos em fontes primárias e secundárias (GIL, 2002).

O trabalho se estrutura nos seguintes tópicos, assim intitulados: As linguagens artísticas na BNCC: proposições e contradições; A questão da competência como princípio norteador da BNCC; As mediações realizadas pelo Estado do Paraná para implementação da BNCC; e A BNCC sob a perspectiva de experiências de ensino de Música nos anos finais do Ensino Fundamental II. As três primeiras partes do trabalho foram realizadas com base em pesquisa bibliográfica documental, já que lida com "documentos oficiais, de projetos políticos, de alcance municipal, estadual e nacional" (MARKONI; LAKATOS, 2002, p. 65-66), que regulamentam e subsidiam os currículos das instituições de ensino brasileiras. Nessas etapas, adotamos estratégias de interpretação e comparação das fontes selecionadas. Na quarta parte do trabalho, adotamos como método o relato de experiência em que, a partir de experiências de ensino de Música no contexto público, foi possível estabelecer relações com as discussões estabelecidas na primeira parte do trabalho. Assim, a narrativa presente neste relato legitima-se na análise documental e no desenvolvimento das práticas e vivências apresentadas.

\section{As linguagens artísticas na bncc: proposições e contradições}

Em sua versão preliminar (BRASIL, 2016), a BNCC trouxe algumas mudanças importantes que, segundo Romanelli (2016, p. 479-480), contribuíram não só para legitimar as especificidades de cada linguagem artística, mas também para validar a necessidade de uma formação específica:

A área de Arte engloba quatro linguagens: Artes Visuais, Dança, Música e Teatro. Cada linguagem tem seu próprio campo epistemológico, seus elementos constitutivos e estatutos, com singularidades que exigem abordagens pedagógicas específicas das artes e, portanto, formação docente especializada (BRASIL, 2016, p. 112).

Contudo, observando a versão oficial da BNCC (BRASIL, 2018), nota-se que a Música, assim como as outras linguagens artísticas, estão inseridas dentro de uma grande área intitulada Linguagens, constituída dos seguintes componentes curriculares: Língua Portuguesa, Arte, Educação Física e Língua Inglesa (BRASIL, 2018, p. 3). Trata-se da única área de conhecimento no documento que está estruturada com subdivisões internas, ou seja, de áreas "menores" denominadas como componentes curriculares, que somadas integram a área de Linguagens. Todavia, as demais áreas de conhecimento como Matemática, Ciências, Geografia, História e Ensino Religioso, por exemplo, são apresentadas separadamente, cada uma com suas respectivas características e com certa independência no sentido de não estarem submetidas a uma determinada área de conhecimento.

Dessa maneira, é possível notar, em primeiro lugar, que há uma hierarquia de importância entre as áreas de conhecimento que integram a base comum curricular: áre- 
as com especificidades epistemológicas asseguradas e áreas dispostas com um menor grau de importância, alocadas em conjunto, a fim de contribuir para uma área "maior" de conhecimento.

Essa subordinação das linguagens artísticas é notada também na subdivisão interna da área de conhecimento. No caso da área de Linguagens, mesmo que de modo implícito, temos o direcionamento dos demais componentes que a integram como meios para contribuir para a Língua Portuguesa. Para elucidar tal ponto de vista, tomemos como exemplo um trecho do próprio documento, que aborda uma das finalidades do ensino de Arte:

[Ensino Fundamental - Anos Iniciais] Tendo em vista o compromisso de assegurar aos alunos o desenvolvimento das competências relacionadas à alfabetização e ao letramento, o componente Arte, ao possibilitar o acesso à leitura, à criação e à produção nas diversas linguagens artísticas, contribui para o desenvolvimento de habilidades relacionadas tanto à linguagem verbal quanto às linguagens não verbais (BRASIL, 2018, p. 199).

O mesmo documento, ao tratar do segundo ciclo do Ensino Fundamental, retoma essa abordagem da finalidade das linguagens artísticas como uma espécie de suporte pedagógico à área de Linguagens:

Desse modo, espera-se que o componente Arte contribua com o aprofundamento das aprendizagens nas diferentes linguagens - e no diálogo entre elas e com as outras áreas do conhecimento -, com vistas a possibilitar aos estudantes maior autonomia nas experiências e vivências artísticas (BRASIL, 2018, p. 205).

Não obstante as observações anteriores, é preciso uma atenção à concepção do componente curricular Arte, que a Música faz parte:

O componente curricular Arte está centrado nas seguintes linguagens: as Artes visuais, a Dança, a Música e o Teatro. Essas linguagens articulam saberes referentes a produtos e fenômenos artísticos e envolvem as práticas de criar, ler, produzir, construir, exteriorizar e refletir sobre formas artísticas. A sensibilidade, a intuição, o pensamento, as emoções e as subjetividades se manifestam como formas de expressão no processo de aprendizagem em Arte (BRASIL, 2018, p. 193).

Com isso, podemos observar que o documento colabora para uma visão artística generalista implicitamente, já que parte do pressuposto de que todas as linguagens artísticas são similares e, portanto, devem ser aglutinadas dentro de um único eixo curricular. Essa é uma maneira indireta de caracterizar cada uma dessas linguagens artísticas como áreas de conhecimento secundárias, como utensílios à construção de um conhecimento "maior".

Além disso, é possível notar, conforme a própria definição do documento, um nivelamento das obras artísticas, das práticas, das habilidades, das técnicas e dos conceitos que as integram, o que pode remeter a uma ideia de que todas as linguagens 
artísticas partem de princípios e processos similares. Dessa forma, ao inferir todas as experiências e produções artísticas sob uma perspectiva comum, abre-se margem para que as particularidades que cada uma das linguagens artísticas possui fique em um segundo plano. Isso, principalmente, se levarmos em consideração que cada uma dessas linguagens artísticas conta com práticas, produções e currículos específicos de ensino e aprendizagem já consolidados.

Assim, a estruturação proposta pela BNCC, ainda que almeje um diálogo entre os diversos fazeres artísticos, dá margem para interpretações e aplicações simplistas e utilitaristas das possibilidades artísticas de ensino e aprendizagem. Desse modo, é possível verificar que a BNCC traz em si uma contradição entre o princípio de especificidade epistemológica das linguagens artísticas, apontado na versão preliminar do documento (BRASIL, 2016), e uma concepção que aloca as linguagens artísticas como partes que se subordinam a um todo, no caso, à área de Linguagens, presente na versão mais recente do documento (BRASIL, 2018).

\section{A questão da competência como princípio norteador da bncc}

O ponto de partida para definir os objetivos da BNCC são os doze direitos à aprendizagem. Constituem um conjunto de proposições que orientam as escolhas feitas pelos componentes curriculares na definição de seus objetivos de aprendizagem (SOUZA e CACIONE, 2018, p. 2). Esses direitos partem da perspectiva de que o aluno deve ser o sujeito das ações pedagógicas no ambiente escolar e, dessa forma, que possa se desenvolver por meio de experiências práticas, diálogo, convívio, expressão e reflexão. Entretanto, segundo Macedo, há algumas contradições presentes na concepção desses direitos de aprendizagem, que cabem a reflexão:

Um dos aspectos que chama a atenção dessa proposta é que tais direitos são direitos do indivíduo, ao mesmo tempo em que são postulados como de todos e para todos. São, portanto, direitos individuais e universais, apresentados como a única forma de garantir a vida democrática. Dessa forma, o entendimento desses direitos à aprendizagem é oriundo de um discurso político particular, no qual a igualdade se alicerça numa semelhança abstrata capaz de garanti-la (MACEDO, 2015, p. 896).

Ou seja, trata-se de uma igualdade formal dos indivíduos perante a lei, que aplicada às diferenças, conflitos e complexidades presentes nos espaços escolares, torna-se algo bastante desafiador em se concretizar. Tomando como base alguns trechos que integram os direitos à aprendizagem, como, por exemplo: "Identificar suas potencialidades, possibilidades, perspectivas e preferências, reconhecendo e buscando superar limitações próprias e de seu contexto" (BRASIL, 2015, p. 8) ou: "Participar ativamente da vida social, cultural e política, de forma solidária, crítica e propositiva, reconhecendo direitos e deveres" (BRASIL, 2015, p. 8), notamos que são proposições que transcendem o próprio âmbito escolar, visto que necessitam de ações integradas de outras instituições, familiares e sociais, e que, além disso, estão sujeitas a aspectos socioeconômicos e da própria particularidade de cada indivíduo. 
Avançando na análise do documento, os princípios norteadores da BNCC (BRASIL, 2018) derivam dos direitos à aprendizagem, sendo, nesse caso, intitulados como competências. São definidos no documento como: [...] a mobilização de conhecimentos (conceitos e procedimentos), habilidades (práticas, cognitivas e socioemocionais), atitudes e valores para resolver demandas complexas da vida cotidiana, do pleno exercício da cidadania e do mundo do trabalho (BRASIL, 2018, p. 8).

A organização dessas competências se dá por meio da seguinte hierarquia: 1) competências gerais da Educação Básica; 2) competências de cada etapa da Educação Básica (Educação Infantil, Ensino Fundamental e Ensino Médio); e 3) competências específicas de cada área de conhecimento. Observando as competências gerais propostas pelo documento, faz-se necessário retomar a mesma crítica a respeito dos doze direitos de aprendizagem feita anteriormente. Segundo Macedo, as competências elencadas são:

[...] uma promessa, por certo, tentadora, de igualdade e inclusão universal, exceto pelo fato de que elas não serão jamais cumpridas. Isto pois o universalismo repousa e sempre repousará, senão em exclusões, pelo menos na indiferença em relação a certas particularidades que ameaçam à abstração (MACEDO, 2015, p. 897).

Essas particularidades, omitidas ou anuladas, integram e constituem cada espaço escolar brasileiro. Tendo isso em vista, não seria mais adequado tomar como base o princípio da diferença para se construir parâmetros mais próximos da realidade escolar? Abordado esse panorama das competências gerais da BNCC, é fundamental discorrermos a respeito das competências específicas, no caso, do componente curricular Arte. Segundo o documento, a abordagem das linguagens artísticas deve ser articulada por meio de seis dimensões do conhecimento: criação, crítica, estesia, expressão, fruição e reflexão (BRASIL, 2018, p. 194-195). Tal proposta, segundo Romanelli:

[...] é um modo promissor de se problematizar o ensino de Arte, já que não parte de modelos utilitaristas, que tratam as linguagens artísticas como mecanismos de desenvolvimento para outras áreas do conhecimento. Isso traz uma possibilidade de concebê-la com uma proposta essencialista, voltada às experiências $e$ aos processos artísticos (ROMANELLI, 2016, p. 480-481).

É um passo inicial importante, como aponta Romanelli: "considerando que as dimensões propostas no documento possam ser revisadas, traduz uma maturidade do ensino da Arte no Brasil, questionando e refutando modelos prontos simplesmente adaptados às nossas escolas" (2016, p. 480). Além disso, a aplicação dessas dimensões do conhecimento ocorre por meio de unidades temáticas, cada uma destinada a tratar uma das linguagens artísticas (Artes Visuais, Dança, Música e Teatro). Tais unidades são destinadas cada uma a um determinado ciclo e ano da Educação Básica e estão estruturadas em objetos de conhecimento (contextos e práticas, elementos da linguagem, materialidades, notação e registro musical e processos de criação) e habilidades (descritas por meio de objetivos de aprendizagem). Ambos objetos de conhecimento e 
habilidades, que devem ser articulados por meio dos seis elementos do conhecimento citados anteriormente. Para discutir de modo mais aprofundado essa dinâmica das unidades temáticas, tomemos como base o quadro a seguir:

\begin{tabular}{|c|c|}
\hline OBJETOS DE CONHECIMENTO & OBJETIVOS DE APRENDIZAGEM \\
\hline Contextos e práticas & $\begin{array}{l}\text { Analisar criticamente, por meio da apreciação musical, usos e } \\
\text { funções da música em seus contextos de produção e circulação, } \\
\text { relacionando as práticas musicais às diferentes dimensões da vida } \\
\text { social, cultural, política, histórica, econômica, estética e ética. } \\
\text { - Explorar e analisar, criticamente, diferentes meios e } \\
\text { equipamentos culturais de circulação da música e do } \\
\text { conhecimento musical. } \\
\text { - Reconhecer e apreciar o papel de músicos e grupos de } \\
\text { música brasileiros e estrangeiros que contribuíram para o } \\
\text { desenvolvimento de formas e gêneros musicais. }\end{array}$ \\
\hline Elementos da linguagem & $\begin{array}{l}\text { - Explorar e analisar elementos constitutivos da música (altura, } \\
\text { intensidade, timbre, melodia, ritmo etc.), por meio de recursos } \\
\text { tecnológicos (games e plataformas digitais), jogos, canções } \\
\text { e práticas diversas de composição/criação, execução e } \\
\text { apreciação musicais. }\end{array}$ \\
\hline Materialidades & $\begin{array}{l}\text { - Explorar e analisar fontes e materiais sonoros em práticas } \\
\text { de composição/criação, execução e apreciação musical, } \\
\text { reconhecendo timbres e características de instrumentos } \\
\text { musicais diversos. }\end{array}$ \\
\hline Notação e registro musical & $\begin{array}{l}\text { - Explorar e identificar diferentes formas de registro } \\
\text { musical (notação musical tradicional, partituras criativas } \\
\text { e procedimentos da música contemporânea), bem como } \\
\text { procedimentos e técnicas de registro em áudio e audiovisual. }\end{array}$ \\
\hline Processos de criação & $\begin{array}{l}\text { - Explorar e criar improvisações, composições, arranjos, jingles, } \\
\text { trilhas sonoras, entre outros, utilizando vozes, sons corporais } \\
\text { e/ou instrumentos acústicos ou eletrônicos, convencionais ou } \\
\text { não convencionais, expressando ideias musicais de maneira } \\
\text { individual, coletiva e colaborativa. }\end{array}$ \\
\hline
\end{tabular}

Quadro 1: Objetos de conhecimento e habilidades da área temática Música - Nono ano - Fundamental II Fonte: BRASIL, 2018, p. 208. Adaptado pelos autores.

Os objetos de conhecimento e as habilidades sugeridas, de modo geral, trazem possibilidades pedagógicas que podem ser desenvolvidas em classe, inclusive de maneira integrada já que, por exemplo, a partir de uma determinada obra musical, é possível abarcar diversos conteúdos e práticas. Todos esses temas estão ligados a elementos formais, experiências práticas e conceitos pertinentes ao desenvolvimento musical do 
aluno, porém, há casos em que as proposições são demasiadamente amplas e, dessa forma, difíceis de serem concretizadas.

Para isso, retomamos, por exemplo, um excerto presente no Quadro 1, relativo ao objeto "Contextos e Práticas": "Analisar criticamente, por meio da apreciação musical, usos e funções da música em seus contextos de produção e circulação, relacionando as práticas musicais às diferentes dimensões da vida social, cultural, política, histórica, econômica, estética e ética" (BRASIL, 2018, p. 208-209). A análise crítica certamente é bem-vinda em qualquer contexto de aprendizagem, mas como promover uma análise tão ampla e complexa, visto que ela demanda ações interdisciplinares, de planejamento a médio e longo prazo, além de recursos didáticos complementares?

Além disso, como os conceitos "cultural, político, histórico, econômico" vão estar presentes na sala de aula sem um amplo projeto interdisciplinar e com disciplinas específicas que aprofundem tais temas? Não seriam questões que, inclusive, chegam a transcender o espaço escolar e, desse modo, demandam a participação e interação com grupos, lideranças ou membros da comunidade, por exemplo, no espaço escolar ou por meio de visitas?

Ainda sobre os apontamentos presentes no Quadro 1, podemos observar itens mais alinhados à realidade escolar, como, por exemplo, "Identificar e analisar diferentes estilos musicais, contextualizando-os no tempo e no espaço, de modo a aprimorar a capacidade de apreciação da estética musical" (BRASIL, 2018, p. 208-209). Nota-se, a partir do exemplo selecionado, proposições mais condizentes de serem planejadas e aplicadas pelos professores. Nesse caso, especificamente, poderiam ser desenvolvidas, por exemplo, atividades baseadas em percepção musical, história, práticas individuais e coletivas, apreciação, criação, escuta etc.

Existem também casos em que há a sugestão de se estabelecer relações pedagógicas com outras áreas de conhecimento, como, por exemplo, cinema e audiovisual, mediadas por meio da utilização de novas tecnologias (BRASIL, 2018, p.189). Nesse caso citado, nota-se que não se leva em consideração fatores cruciais, como a maioria das escolas e dos alunos não possuir recursos adequados para a realização de produção de material para mídias.

A respeito dessas habilidades propostas para a "Área Temática Música", constatamos que há proposições mais próximas da realidade escolar, possíveis de serem desenvolvidas em sala, e outras que dificilmente podem ser cumpridas em sua totalidade, seja por estarem dispostas de uma maneira muito genérica, seja por não levarem em consideração as características e dinâmicas do ambiente escolar.

Após a publicação da versão oficial da BNCC, professores e demais profissionais da Educação têm tido a oportunidade de contribuir, por meio de comentários no próprio site do Ministério da Educação, em que uma versão digital da BNCC fica disponível em formato de planilha. Nesse documento digital, há uma aba intitulada "Arte Comentada", em que é possível inserir sugestões de ajustes e, dessa maneira, contribuir na composição de um material suplementar para redatores do currículo. Para tanto, selecionamos 
algumas dessas ideias e as apresentamos no quadro a seguir, dividido em comentários e possibilidades. É importante salientar que esse suplemento não apresenta quais são os autores das sugestões:

\begin{tabular}{|c|c|}
\hline COMENTÁRIOS & POSSIBILIDADES \\
\hline $\begin{array}{l}\text { - Avaliar os papéis e as aplicações da música, } \\
\text { ampliando a escuta e a análise dos materiais } \\
\text { sonoros de diversos períodos e momentos } \\
\text { sociais brasileiros e de outros países, } \\
\text { estabelecendo relações entre suas funções e } \\
\text { seus contextos social e de circulação. }\end{array}$ & $\begin{array}{l}\text { - Explicitar habilidades ligadas à apreciação } \\
\text { de manifestações musicais específicas e } \\
\text { à pesquisa sobre o contexto, para que os } \\
\text { alunos estabelecem os porquês de cada } \\
\text { manifestação, como as que trabalham } \\
\text { questões sociais e culturais. O professor pode } \\
\text { propor fazeres musicais com os instrumentos } \\
\text { formais ou alternativos. } \\
\text { - Nesta habilidade, há oportunidade, também, } \\
\text { de estabelecer relação com o artigo } 26-A \text { da } \\
\text { Lei no } 9.394, \text { que propõe conteúdos referentes } \\
\text { à história e à cultura afro-brasileira e indígena } \\
\text { nos currículos. }\end{array}$ \\
\hline $\begin{array}{l}\text { Conhecer, investigar e avaliar criticamente } \\
\text { meios e equipamentos culturais diversos, } \\
\text { refletindo sobre seus usos e funções. } \\
\text { Conscientizar de que um mesmo local pode ser } \\
\text { compreendido como lugar de aprendizagem, } \\
\text { ou de apresentação musical, de razão e função } \\
\text { diferenciada, midiática ou social. }\end{array}$ & $\begin{array}{l}\text { - Explicitar as inúmeras possibilidades de espaços } \\
\text { de criação, ensaio e apresentação, para maior } \\
\text { compreensão e percepção dos alunos sobre as } \\
\text { potencialidades dos três níveis. } \\
\text { - Propor o acesso a registros musicais } \\
\text { diversificados no uso de um mesmo espaço } \\
\text { em diferentes contextos: no desenvolvimento } \\
\text { musical, com ou sem a interação do público, } \\
\text { no registro ou na transmissão em mídias. }\end{array}$ \\
\hline $\begin{array}{l}\text { Identificar, apreciar, caracterizar e avaliar a } \\
\text { criação singular de um profissional ou uma } \\
\text { banda. Contextualizar o surgimento de um } \\
\text { gênero musical e a contribuição de um } \\
\text { músico ou grupo de músicos. }\end{array}$ & $\begin{array}{l}\text { - Propor conhecer a importância do } \\
\text { trabalho de um artista ou de uma banda } \\
\text { com a compreensão e a separação entre } \\
\text { desenvolvimento musical e construção } \\
\text { midiática de um gênero musical. }\end{array}$ \\
\hline
\end{tabular}

Quadro 2: Trecho de material suplementar para o redator do currículo - Anos finais do Ensino Fundamental II Fonte: BRASIL, 2018, p. 208. Adaptado pelos autores.

Esses comentários apresentados são oriundos da versão virtual da BNCC (BRASIL, 2018), alocada no site do Ministério da Educação, com a possibilidade daqueles que a acessam realizarem complementações, sugestões ou comentários a respeito das disposições que integram o documento. Inclusive, o conteúdo do Quadro 2 demonstra alguns ajustes possíveis para as reformulações futuras do documento e, até lá, podem servir para auxiliar docentes e gestores em seus processos de elaboração e aplicação de propostas pedagógicas. 
Sintetizando as análises apresentadas nesta etapa do trabalho, podemos notar que as competências gerais e específicas propostas pela BNCC e as dimensões do conhecimento das linguagens artísticas estão dispostas em sucessivas tentativas de conciliar perspectivas antagônicas: a arte como utilidade (ou ferramenta) e a arte como essência (experiência e processo); a especificidade das linguagens artísticas e a simplificação delas como oriundas de um mesmo princípio e procedimentos; e o foco no desenvolvimento individual, mas norteado por uma perspectiva generalista, que anula ou ignora as diferenças.

\section{As mediações realizadas pelo estado do paraná para implementação da bncc}

Cada região brasileira vem realizando as reformulações curriculares de suas instituições de ensino com base nas diretrizes propostas pela BNCC. Para abordar essa questão, tomamos como exemplo os processos de adaptação curricular realizados pelo estado do Paraná. Para isso, o estado paranaense elaborou uma versão preliminar de um documento orientador dos currículos, chamado Referencial Curricular do Paraná: Princípios, direitos e orientações - RCP (PARANÁ, 2018), que está estruturado em três partes. Nas duas primeiras, são apresentadas as definições de princípios e direitos de aprendizagem, embasados em documentos como LDB (BRASIL, 1996), BNCC (BRASIL, 2018) e Estatuto da Criança e Adolescente (BRASIL, 1990).

Nessas primeiras etapas, as concepções apresentadas no RCP seguem a mesma linha conceitual e descritiva da BNCC, embora haja termos específicos com nomenclaturas distintas entre os dois documentos, como, por exemplo: competências gerais (BNCC) $x$ direitos de aprendizagem (RCP); e competências específicas (BNCC) $x$ objetivos de aprendizagem (RCP). Na terceira parte do documento, ocorre a apresentação da organização curricular e dos objetivos de aprendizagem. Como nas partes anteriores, esta possui um formato bastante similar ao documento da BNCC: delimitações e as proposições gerais para cada ciclo de aprendizagem e, na sequência, a relação de objetivos de aprendizagem para cada área de conhecimento.

Com esse panorama traçado, podemos observar que o RCP é uma adaptação bastante próxima dos princípios e estruturas que regem a BNCC. A ideia original de base comum curricular é, como o documento propõe, a de proporcionar parâmetros elementares de equidade na aprendizagem da Educação Básica para que, por meio desses pontos norteadores, cada região discuta e reconfigure suas próprias propostas curriculares, integrando os parâmetros nacionais às características e demandas regionais.

Porém, o que se observa no documento paranaense é uma atenção maior em atender às demandas normativas da BNCC, do que propriamente em discutir e elaborar proposições pedagógicas que articulem expectativas pedagógicas nacionais e regionais. Tanto é que as críticas realizadas à BNCC nas etapas anteriores deste estudo podem ser replicadas ao documento paranaense. Nessa lógica, podemos citar algumas delas novamente, como, por exemplo: a questão da área Linguagens e das linguagens 
artísticas sem uma especificidade epistemológica assegurada ou mesmo a existência de alguns objetivos de aprendizagem conflitantes, seja por demasiada abrangência ou por proposições incompativeis com a estrutura e a organização escolar.

Além desses aspectos gerais, é interessante observar como o RCP adota algumas estratégias para especificar e aprofundar os objetivos de aprendizagem das áreas temáticas. Vejamos, a seguir, um quadro que demonstra esse tipo de iniciativa:

\begin{tabular}{|c|c|c|}
\hline $\begin{array}{l}\text { UNIDADE } \\
\text { TEMÁTICA }\end{array}$ & $\begin{array}{c}\text { OBJETOS DE } \\
\text { CONHECIMENTO }\end{array}$ & OBJETIVOS DE APRENDIZAGEM \\
\hline & & $\begin{array}{l}\text { (EF69AR16) Analisar criticamente, por meio da apreciação } \\
\text { musical, usos e funções da música em seus contextos de } \\
\text { produção e circulação, relacionando as práticas musicais } \\
\text { às diferentes dimensões da vida social, cultural, política, } \\
\text { histórica, econômica, estética e ética. } \\
\text { - Perceber a função social e ideológica da música dos } \\
\text { diferentes povos. } \\
\text { - Apreciar gêneros musicais urbanos... RAP (cultura hip-hop). } \\
\text { - Explorar e apreciar a música engajada, música popular } \\
\text { brasileira e a música contemporânea, entendendo o } \\
\text { processo de produção e execução, considerando a época e } \\
\text { as influências políticas e culturais. } \\
\text { - Reconhecer a MPB - samba, choro, entre outros. }\end{array}$ \\
\hline Música & $\begin{array}{c}\text { Contextos e } \\
\text { práticas }\end{array}$ & $\begin{array}{l}\text { (EF69AR17) Explorar e analisar, criticamente, diferentes } \\
\text { meios e equipamentos culturais de circulação da música e do } \\
\text { conhecimento musical. } \\
\text { - } \quad \begin{array}{l}\text { Identificar produções musicais nas mídias - (cinema e } \\
\text { internet). }\end{array} \\
\text { - Explorar e apreciar a música engajada, música popular } \\
\text { brasileira, entendendo o processo de produção e execução, } \\
\text { considerando a época e as influências politicas e culturais. } \\
\text { - Entender e vivenciar a função da música nos diferentes } \\
\text { espaços de divulgação de práticas artísticas: museu, } \\
\text { biblioteca, internet, patrimônio cultural, entre outros, } \\
\text { destacando suas vivências regionais. } \\
\text { - Conhecer a história do Rádio, da TV, da MPB com seus } \\
\text { movimentos e gêneros musicais. } \\
\text { Conhecer os elementos musicais: melodia, harmonia e ritmo. }\end{array}$ \\
\hline
\end{tabular}

Quadro 3: Trecho de objetivos de aprendizagem propostos para a unidade temática Música - Nono ano do Ensino Fundamental - Referencial Curricular Paranaense Fonte: PARANÁ, 2018, p. 298. Adaptado pelos autores (grifos nossos). 
Apesar dos problemas apontados sobre os generalismos e as contradições presentes em alguns dos objetivos de aprendizagem propostos, tanto na BNCC quanto no $\mathrm{RCP}$, o documento paranaense apresenta um avanço significativo ao elencar, com base em um objetivo geral, objetivos específicos que trazem algum tipo de direcionamento de contexto, conteúdo ou tipos de atividades, por exemplo: "[...] apreciar gêneros musicais urbanos RAP (cultura hip-hop)" ou "[...] identificar produções musicais nas mídias (cinema e internet)".

Essas ações de direcionamento mais específico dos objetivos são fundamentais para que o professor possa se posicionar diante do que está sendo proposto. Assim, com um posicionamento mais claro, há a possibilidade de se tomar um determinado objetivo como base, adaptá-lo ou, ainda, construir argumentos que contestem sua aplicação e, nesse caso, articular outras possibilidades pedagógicas que sejam mais coerentes a determinado contexto escolar.

No ano posterior à publicação do RCP, o Estado do Paraná elaborou um documento complementar, em uma versão preliminar, denominado "Currículo da Rede Estadual Paranaense - CREP" (PARANÁ, 2019a). Esse documento traz conteúdos essenciais para cada componente curricular em cada ano do Ensino Fundamental. No ano de 2019: "a versão preliminar do CREP passou por um processo de consulta pública, recebendo contribuições e ajustes" (PARANÁ, 2021). Em 2020, o CREP passou a ser o documento norteador das propostas pedagógicas curriculares (PPCs) das escolas paranaenses e a servir como referência para os planejamentos gerais e planos de aula dos professores da rede estadual.

Um diferencial do CREP em relação aos outros documentos apresentados anteriormente é a sugestão de distribuição temporal dos conteúdos nos trimestres ao longo do ano letivo. A esse respeito:

Essa organização visa a fortalecer o apoio didático ao processo de ensino-aprendizagem, trazendo maior clareza dos conteúdos que darão suporte para o desenvolvimento dos objetivos de aprendizagem, assim como consolidar o trabalho na rede estadual de ensino. [...] Também ressalta-se que as listagens de conteúdos não inviabilizam as especificidades e peculiares necessárias para atender as [sic] diferentes realidades locais e regionais das escolas paranaenses. Essas especificidades devem ser respeitadas e incluídas nas Propostas Pedagógicas Curriculares (PPC) (PARANÁ, 2021).

Vejamos, a seguir, um exemplo desse formato proposto pelo CREP: 


\begin{tabular}{|c|c|c|c|c|c|}
\hline $\begin{array}{l}\text { UNIDADE } \\
\text { TEMÁTICA }\end{array}$ & $\begin{array}{l}\text { OBJETOS DE } \\
\text { CONHECIMENTO }\end{array}$ & CÓDIGO & $\begin{array}{l}\text { OBJETIVOS DE } \\
\text { CONHECIMENTO }\end{array}$ & CONTEÚDOS & TRIMESTRE \\
\hline \multirow{4}{*}{ Música } & \multirow{4}{*}{$\begin{array}{l}\text { Contextos e } \\
\text { práticas }\end{array}$} & PR.EF69AR16.a.9.34 & $\begin{array}{c}\text { Explorar e apreciar a } \\
\text { música engajada, música } \\
\text { popular brasileira e a } \\
\text { música contemporânea, } \\
\text { entendendo o processo } \\
\text { de produção e } \\
\text { execução, considerando } \\
\text { a época e as influências } \\
\text { políticas e culturais. }\end{array}$ & \multirow{4}{*}{$\begin{array}{l}\text { Música } \\
\text { Contemporânea. } \\
\text { Música nas } \\
\text { mídias: cinema, tv, } \\
\text { propaganda etc. }\end{array}$} & \multirow{4}{*}{$1^{\circ}$ - } \\
\hline & & PR.EF69AR17.s.9.35 & $\begin{array}{l}\text { Explorar e analisar, } \\
\text { criticamente, diferentes } \\
\text { meios e equipamentos } \\
\text { culturais de circulação } \\
\text { da música e do } \\
\text { conhecimento musical. }\end{array}$ & & \\
\hline & & PR.EF69AR17.a.9.36 & $\begin{array}{l}\text { Identificar produções } \\
\text { musicais nas mídias - } \\
\text { (cinema e internet). }\end{array}$ & & \\
\hline & & PR.EF69AR17.a.9.38 & $\begin{array}{l}\text { Entender e vivenciar } \\
\text { a função da música } \\
\text { nos diferentes espaços } \\
\text { de divulgação de } \\
\text { práticas artísticas: } \\
\text { museu, biblioteca, } \\
\text { internet, patrimônio } \\
\text { cultural, entre outros, } \\
\text { destacando suas } \\
\text { vivências regionais. }\end{array}$ & & \\
\hline
\end{tabular}

Quadro 4: Trecho de objetivos de aprendizagem propostos para a unidade temática Música Nono ano do Ensino Fundamental - Currículo da Rede Estadual Paranaense - Caderno Arte Fonte: PARANÁ, 2019b, p. 184. Adaptado pelos autores.

Além da proposição de conteúdos e do período de aplicação, há uma coluna com códigos específicos relacionados aos objetivos do RCP. Esses códigos, segundo a Secretaria da Educação do Paraná: "foram criados para apoiar os professores no momento de organizar seus planos de aula e para realizarem o Registro de Classe On-line, referido pela sigla RCO" (PARANÁ, 2019c). Esse registro é feito por meio de um software, que permite ao professor registrar em tempo real conteúdos, avaliações e frequências dos alunos, sem a necessidade do tradicional registro de classe impresso. 


\section{Reformas curriculares com base em experiências de ensino de música nos anos finais do ensino fundamental II}

Nessa etapa, pretendemos tratar sobre como a reestruturação curricular na Educação Básica tem afetado as práticas pedagógicas dos professores de Música na Educação Básica. A partir dessas discussões, tencionamos compartilhar algumas possíveis ações para mediar as proposições curriculares nacionais e estaduais. Para isso, tomamos como base algumas experiências de ensino de Música oriundas de atividades de estágio curricular obrigatório do curso de Licenciatura em Música da Universidade Estadual de Londrina (UEL), ocorridas durante o ano letivo de 2019.

As atividades de ensino relatadas foram realizadas no formato de Grupo Multiserial de Estágio e Prática de Ensino (GMEPE). Trata-se de um modelo de estágio supervisionado, constituído por dois estudantes de cada ano do curso de Licenciatura em Música da UEL (LOUREIRO, 2006, p. 26-27). A supervisão dessas atividades ocorre de forma direta, com um professor da área de educação musical acompanhando e orientando os alunos durante as práticas pedagógicas. O GMEPE acontece semanalmente em uma escola da rede pública, em que:

Os alunos do primeiro e segundo ano atuam como observadores, os alunos do terceiro ano atuam como professores de uma das turmas, em dupla, durante todo o ano letivo e os alunos do quarto ano atuam individualmente como professores de uma outra turma, durante um semestre (SONSIN et al, 2019, p. 2).

As aulas e as turmas são cedidas por um professor da área de Arte, que integra o núcleo docente do colégio e participa de forma ativa nas experiências de estágio do grupo, compartilhando seus planejamentos, registros de classe (conteúdos e presença), avaliações e participando de reuniões realizadas no próprio ambiente escolar, após as aulas aplicadas pelos estagiários. Nessas experiências de estágio supervisionado, foram cedidas duas turmas de nono ano (anos finais do segundo ciclo do Ensino Fundamental), cada turma teve uma aula de música, com duração de cinquenta minutos, uma vez por semana.

As experiências aqui relatadas foram realizadas durante o ano letivo de 2019, em dois colégios da rede estadual paranaense, o Colégio Estadual Ana Molina Garcia e o Colégio Estadual Professora Kazuko Ohara, ambos com suas atividades de ensino voltadas ao segundo ciclo do Ensino Fundamental. Os professores de Arte desses colégios citados têm sua formação em Licenciatura em Música e atuam nesses contextos escolares, de acordo com as bases curriculares paranaenses vigentes, no caso, o RCP e o CREP.

Outro aspecto importante a ser ressaltado está relacionado às rotinas e aos prazos de registros de aula, presença e avaliações, realizados por meio do Registro de Classe On-line (RCO). Nesse sistema de registro proposto, há uma padronização dos objetivos e conteúdos que devem ser tratados em sala. Assim, no primeiro trimestre do ano letivo, por exemplo, todos os professores de Arte da rede estadual paranaense têm de abordar os mesmos objetivos e conteúdos dispostos nos documentos norteadores (RCP e CREP), dentro do prazo proposto. Essa é uma medida que, por um lado, otimiza a gestão 
e o controle do sistema de ensino paranaense, mas, por outro lado, acaba reduzindo as possibilidades pedagógicas dos professores, já que inviabiliza a abordagem de objetivos ou conteúdos que não estejam elencados no sistema de registro.

A respeito dessas regulações de registro propostas, temos ainda a questão da avaliação. Para cada aula, deve ser atribuída uma atividade de avaliação quantitativa (nota), o que acaba não só gerando uma demanda burocrática ao professor, de sucessivas correções de atividades, como também condicionando os alunos a realizarem as atividades com o foco na nota e não na experiência. Com base nesses balizadores de planejamento e nas sucessivas rotinas de registro impostas, os professores podem ficar sobrecarregados, já que precisam cumprir as demandas de metas e prazos estabelecidos e, ao mesmo tempo, levar em consideração as particularidades de cada turma e cada aluno durante os processos de ensino e aprendizagem. É importante considerar também que esse formato proposto acaba deixando de lado outros tipos de avaliação fundamentais às experiências musicais como, por exemplo, a avaliação qualitativa e a avaliação processual.

Além dessas questões, outro fator determinante é a quantidade de aulas de Arte destinadas a cada turma: duas aulas semanais. Nesse contexto, há uma tarefa difícil para o professor de Arte em desenvolver experiências de ensino e aprendizagem profundas e continuadas frente à demanda de variedade e complexidade de objetivos e conteúdos, ainda mais com prazos de aplicação e avaliação predeterminados.

Contudo, é preciso salientar também que, apesar dessas dificuldades pedagógicas apresentadas, os professores de ambos os colégios relataram que têm conseguido gradativamente desenvolver estratégias para encontrar pontos de contato entre as proposições institucionais e as especificidades de seus contextos escolares. Os planejamentos pedagógicos coletivos e as ações de formação continuada são algumas das ações que viabilizam a reflexão e o desenvolvimento de ações pedagógicas a fim de mediar as novas demandas curriculares propostas. Ademais, a atuação das representações de classe (sindicatos e representantes docentes) em debates educacionais locais e regionais tem sido um fator importante para tensionar as instituições governamentais a rever posturas e proposições curriculares que destoam da realidade escolar.

Tendo em vista esse panorama, as propostas realizadas pelo grupo de estágio foram planejadas em parceria com os professores de Arte de cada colégio, levando em consideração não só as proposições institucionais de objetivos, conteúdos, prazos e avaliações, como também os desafios pedagógicos mencionados no decorrer do trabalho, medidas a fim de buscar formas de alinhar as práticas pedagógicas em sala às proposições curriculares institucionais, sem deixar de lado a realidade de cada colégio.

Cada proposta de ensino de Música aplicada nos colégios citados foi estruturada com base em um tema central, que norteou a realização das propostas durante o ano letivo de 2019. No Colégio Kazuko Ohara, foram desenvolvidas propostas pautadas nos temas "trilha sonora" e "prática instrumental e vocal coletiva". Já no Colégio Ana Molina Garcia, foram desenvolvidas propostas pautadas nos temas "consciência rítmica" e "rádio na escola". A escolha desses temas partiu de uma avaliação prévia que o grupo de estágio realizou com as turmas, por meio de um questionário com o objetivo de verificar a experiência musical dos 
alunos e a expectativa com as aulas de Música. Com base nessas respostas, o grupo pôde avaliar e ajustar as propostas para os contextos distintos.

A organização dessas propostas por temas fomentou o desenvolvimento de objetivos, conteúdos e atividades que, mesmo em formato e estrutura diferentes do que foi proposto institucionalmente aos professores estaduais, foram ações pedagógicas que dialogaram com as demandas curriculares necessárias a serem cumpridas. Para isso, os estagiários incorporaram os objetivos e os conteúdos específicos da faixa etária abordada sugeridos pelos documentos (RCP e CREP), além dos ajustes e complementos, por meio de objetivos específicos e conteúdos não elencados nos documentos.

Por exemplo, a proposta de "rádio na escola" está relacionada ao objetivo de conhecimento (Quadro 4): "Explorar e analisar, criticamente, diferentes meios e equipamentos culturais de circulação da música e do conhecimento musical" (PARANÁ, 2019b, p. 184). Na proposta dos estagiários, esse objetivo foi adaptado para: "Vivenciar processos de elaboração de um programa de rádio sobre música e sobre a escola/bairro". Tomando como base ainda esse exemplo de objetivo geral, podemos apresentar objetivos específicos derivados e ainda demonstrar como foram organizados, no caso, em quatro unidades didáticas, cada uma destinada a um trimestre escolar:

\begin{tabular}{|c|l|}
\hline UNIDADE DIDÁTICA & \multicolumn{1}{c|}{ OBJETIVOS ESPECÍFICOS } \\
\hline Unidade 1 & $\begin{array}{l}\text { Conhecer aspectos gerais sobre o rádio como veículo de comunicação: } \\
\text { história da rádio, função social, meios de difusão da música. }\end{array}$ \\
\hline Unidade 2 & $\begin{array}{l}\text { Atentar-se à diversidade de repertório e gêneros musicais presentes } \\
\text { na rádio. }\end{array}$ \\
\hline Unidade 3 & $\begin{array}{l}\text { Atentar-se para alguns elementos estruturantes da música (ritmo, } \\
\text { melodia, harmonia). }\end{array}$ \\
\hline Unidade 4 & $\begin{array}{l}\text { Pesquisar a vivência musical da comunidade escolar e do bairro, roteiros } \\
\text { de entrevista e estratégias de gravação e transcrição de relatos. }\end{array}$ \\
\hline - $\begin{array}{l}\text { Conhecer o roteiro de um programa radiofônico e, com as entrevistas } \\
\text { realizadas, criar um programa radiofônico. } \\
\text { Gravar e editar o programa de rádio feito por eles. Equipamentos de } \\
\text { gravação, gravação do programa, montagem e edição do programa, } \\
\text { publicação do programa em algum lugar acessivel. }\end{array}$ \\
\hline
\end{tabular}

Quadro 5: Exemplo de objetivos específicos para uma proposta musical Fonte: FRANZIM, 2019 p. 12-13. Adaptado pelos autores.

Observando a proposta tomada como exemplo, é possível notar que há outras possibilidades para se estruturar um planejamento de acordo com as características da turma e o contexto do colégio. Tudo isso sem deixar de dialogar com as bases curriculares propostas. 
Durante as aulas de música, os professores de Arte disponibilizaram o acesso dos estagiários ao sistema de Registro de Classe On-line (RCO), possibilitando que o grupo vivenciasse as mediações necessárias tanto de planejamento, como de registro de conteúdos, presença e avaliação. Essa experiência se mostrou bastante positiva aos estagiários, que puderam conhecer as rotinas características de um docente da educação básica, refletir e elaborar estratégias para lidar com as limitações ainda presentes nesse tipo de registro, principalmente relacionadas aos conteúdos e tipos de avaliação que o sistema ainda não possui cadastrado.

Outro aspecto importante a ser relatado durantes essas experiências de estágio é a questão do espaço escolar. É preciso levar em consideração, preliminarmente, que são colégios públicos, planejados sob uma perspectiva oriunda de uma outra época e uma outra concepção de educação, voltadas exclusivamente para o letramento. As reestruturações curriculares, a partir da Lei das Diretrizes e Bases (LDB) (BRASIL, 1996), reintegraram as linguagens artísticas ao conteúdo curricular obrigatório, porém, foram novas proposições aplicadas em escolas com estruturas físicas (prediais) oriundas de um projeto educacional anterior. Portanto, até os dias atuais, os professores de Arte enfrentam essa problemática de um espaço adequado para o desenvolvimento das atividades artísticas. Em contrapartida, as demandas curriculares propostas pelas instituições nacionais e estaduais não levam em consideração essa defasagem estrutural, que é elementar para que as proposições feitas possam ser aplicadas adequadamente. Contudo, é preciso considerar adaptações e readequações gradativas nos colégios públicos por parte do poder público, observadas principalmente pela implantação de novos espaços e recursos, como os laboratórios de informática, bibliotecas, salas multimeios (com equipamentos eletrônicos) e quadras poliesportivas.

Ambos os colégios onde as propostas pedagógicas se desenvolveram não possuem espaços específicos destinados às atividades artísticas. No caso da Música, o Colégio Ana Molina ainda conta com um acervo de instrumentos musicais (instrumentos de percussão diversos, violões, teclado e flautas doce). Já o Colégio Kazuko Ohara não possui instrumentos musicais. Para viabilizar as atividades práticas, em ambos os colégios, o grupo de estágio utilizou os instrumentos musicais e equipamentos de som cedidos pelo Departamento de Música da Universidade Estadual de Londrina.

Essa integração entre universidade e escola pública foi algo fundamental não só para viabilizar e ampliar as possibilidades pedagógicas dos grupos de estágio nos colégios públicos, mas também cumpriu um importante papel ao gerar um senso de pertencimento das atividades musicais à comunidade escolar. A partir da presença do grupo de estágio no ambiente escolar e do desenvolvimento de suas ações (atividades práticas, circulação de instrumentos e equipamentos, apresentações etc.), a comunidade escolar (familiares, professores, funcionários e os próprios alunos) começou a interagir e a contribuir para promover condições adequadas para o desenvolvimento das aulas de música. Doações de instrumentos musicais, materiais (cds, dvds e livros) e sugestões de espaços ou alternativas para o desenvolvimento das atividades foram algumas das iniciativas que partiram dos membros da comunidade escolar, em apoio às atividades 
de ensino de música. Assim, mesmo com as dificuldades de espaço e recursos materiais presentes nesses espaços, foi possível, por meio da participação da comunidade escolar, desenvolver estratégias para contornar tais desafios e, dessa forma, desenvolver atividades de ensino musical significativas para os alunos desses espaços escolares.

Ainda sobre a questão do espaço escolar, é importante relatar as estratégias de mapeamento realizadas pelo grupo de estágio para compreender as dificuldades e possibilidades no ambiente escolar. Para tal, o grupo de estágio levou em consideração que a aplicação das atividades musicais muitas vezes demanda experimentações e expressões sonoras, por meio da voz, do corpo ou de instrumentos musicais tradicionais ou não convencionais. Assim, pela ausência de um espaço adequado no ambiente escolar, tais práticas podem gerar tensões nas rotinas do colégio, pois existem outras áreas de conhecimento, com características e dinâmicas distintas, acontecendo simultaneamente em um mesmo ambiente.

Após o grupo de estágio mapear essas dinâmicas de funcionamento dos colégios, foram elencadas algumas estratégias de utilização de espaços alternativos, de acordo com a natureza das atividades musicais a serem desenvolvidas: 1) As atividades de escuta, diálogo e exposição de conceitos foram realizadas na sala de aula tradicional; 2) As atividades envolvendo criação, experimentação e composição com instrumentos musicais, fontes sonoras e canto foram realizadas em espaços alternativos, como laboratórios de informática e áreas externas (palco ou pátio); 3) As atividades de prática coletiva, instrumental e vocal foram realizadas nas quadras poliesportivas; e 4) As atividades em grupo foram distribuídas entre os espaços alternativos descritos e com a presença de um estagiário em cada grupo. A seguir, alguns registros ${ }^{4}$ da utilização desses espaços:

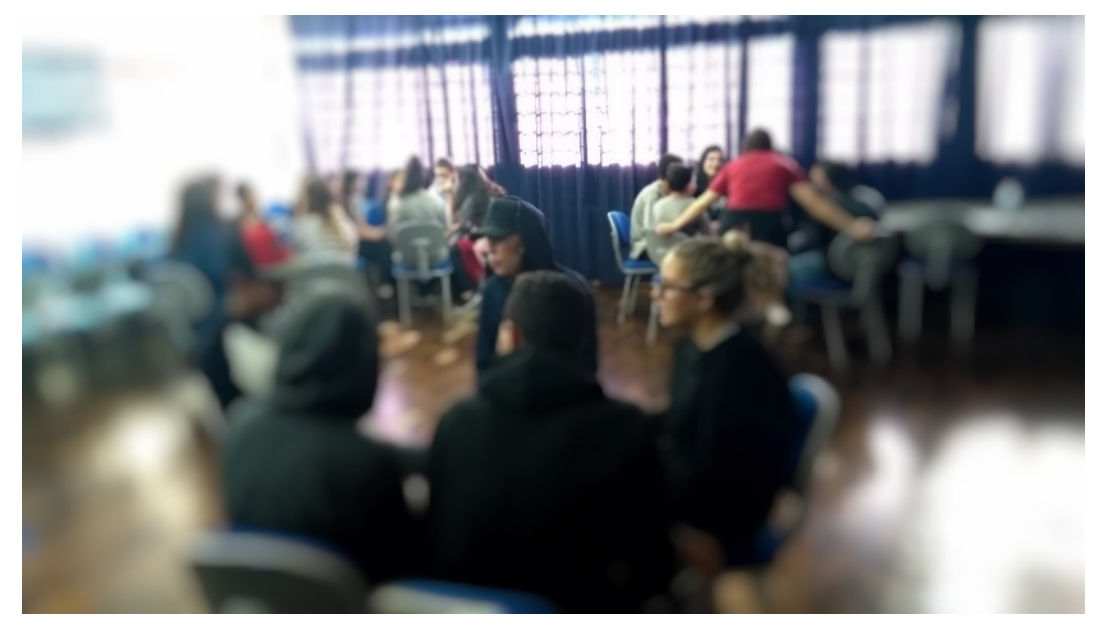

Figura 2: Trabalho em grupo para criação de uma canção realizada no laboratório de informática do Colégio Kazuko Ohara

Fonte: Registro dos autores, 2019.

4 Os registros fotográficos compartilhados neste trabalho (Figura 1 e Figura 2) são oriundos de atividades de estágio supervisionado, cuja a autorização do uso de imagens é cedida através de termo assinado em comum acordo entre as partes envolvidas (universidade, escola, estagiários, alunos e professor supervisor) para fins pedagógicos e de divulgação científica. Contudo, por se tratarem de registros que envolvem participantes menores de idade, optamos por expor tais registros preservando a identidade dos envolvidos. 
Nesse exemplo, temos uma atividade de criação de letra para uma canção, em que foi fundamental o trabalho em grupos menores, de três a cinco alunos. Para isso, foi utilizado como espaço alternativo a sala multimeios do Colégio Kazuko Ohara, ambiente que propiciou uma maior liberdade de diálogo, experimentação e criação musical de cada grupo.

Essas estratégias de uso de espaços alternativos foram fundamentais para que as propostas pudessem abordar experiências musicais diversas. A utilização desses espaços para suprir as necessidades estruturais e de recursos materiais inerentes às aulas de música claramente gerou uma demanda de organização e reorganização dos espaços, antes e após cada uma das aulas, porém, tais dificuldades puderam ser contornadas ao se integrar alunos, professores e funcionários nesses processos de adaptação.

Por fim, no que tange ao tema das reestruturações curriculares da Educação Básica, com base nas experiências de ensino de Música relatadas, podemos concluir que algumas das proposições curriculares presentes nos documentos BNCC, RCP e CREP se tornam bastante desafiadoras quando defrontadas com a realidade da escola pública, como, por exemplo, a ausência de recursos e de espaços adequados para as experiências artísticas ou até as proposições institucionais que acabam limitando as possibilidades de planejamento e realização de aulas advindas do professor.

Contudo, as ações realizadas pelo grupo de estágio, mesmo que de modo pontual, mostram que é possível estabelecer um diálogo entre as proposições curriculares e o contexto de uma determinada turma de alunos, porém, é um processo que demanda, como descrito durante essa etapa, revisar e adaptar de forma crítica, a partir da perspectiva dos alunos, os objetivos e conteúdos propostos preliminarmente pelas instituições governamentais e, além disso, buscar consolidar, ainda que de forma alternativa, uma estrutura mínima de recursos adequados para o ensino de música.

\section{Considerações finais}

Este trabalho teve como objetivo discutir sobre as reformas curriculares na Educação Básica sob três perspectivas: BNCC, mediações estaduais e experiências de ensino de música em escolas públicas. As argumentações do trabalho foram iniciadas por uma análise crítica da BNCC, abordando aspectos como a estruturação da área de Arte, as concepções e as proposições das linguagens artísticas, incluindo as competências gerais e específicas. Em seguida, propusemos uma breve análise de como as instituições estaduais efetuam as mediações da base comum para contextos regionais específicos, por meio do Referencial Curricular Paranaense (RCP) e do Currículo da Rede Estadual Paranaense (CREP). Por fim, discutimos como os professores de Música lidam com a proposições curriculares nacionais (BNCC) e estaduais (RCP e CREP) no ambiente escolar. Para isso, tomamos como base experiências de ensino e aprendizagem em Música vivenciadas com turmas dos anos finais do segundo ciclo do Ensino Fundamental de colégios públicos londrinenses.

Com base nas análises realizadas, podemos apontar que as reformas curriculares propostas pela BNCC partem de uma iniciativa de inclusão, equidade e democratização 
do ensino na Educação Básica, mas ainda apresentam aspectos de estruturação e concepção que trazem consigo contradições internas, como: a Arte como utilidade ou a Arte como essência; a especificidade epistemológica ou a simplificação das linguagens artísticas; e o foco no desenvolvimento individual ou na perspectiva generalista. São contraposições desafiadoras para que os professores possam, a partir delas, desenvolverem suas atividades pedagógicas.

Na perspectiva estadual, apontamos que a reformulação curricular no contexto paranaense ocorreu inicialmente de forma bastante alinhada à BNCC, não só pela reprodução de suas estruturas, concepções e direcionamentos, mas por incorporar suas problemáticas e contradições sem uma devida crítica ou sugestão de readequações necessárias para uma maior coerência ao processo de reformulação curricular.

Em um segundo momento, atentamos aos avanços significativos das instituições educacionais do Paraná, buscando ajustar as proposições curriculares iniciais, presentes no Referencial Curricular Paranaense. A partir do CREP e do RCO, mais especificamente, por meio da proposição de objetivos específicos, conteúdos e organização curricular mais claros e condizentes à realidade escolar, houve uma melhora significativa no direcionamento dos planejamentos pedagógicos das escolas e dos professores. Entretanto, tratam-se ainda de iniciativas mais propensas à regulação e ao cumprimento de diretrizes curriculares do que propriamente voltadas ao aperfeiçoamento dos processos de ensino e aprendizagem na Educação Básica. Espera-se que nas revisões curriculares futuras seja possível buscar um processo de mediação das bases curriculares mais equilibrado entre proposições nacionais e demandas regionais.

Por meio do relato de experiência do estágio curricular em Música aplicado em escolas públicas paranaenses, discutimos como as reformas curriculares propostas pelas instituições de âmbito nacional e estadual têm impactado nas rotinas dos professores da escola pública. Além disso, foi possível notar que, apesar das dificuldades presentes na educação básica pública, é viável desenvolver propostas pedagógicas norteadas por outras formas de planejamento, distintas daquelas propostas pelos documentos da BNCC, RCP e CREP, correspondendo ainda aos objetivos, conteúdos e processos de aprendizagem regulamentados pelas instituições educacionais.

A pesquisa prévia sobre a experiência musical dos alunos, o planejamento pelos temas geradores, as estratégias de utilização de espaços de ensino alternativos e a integração da comunidade escolar às ações de ensino de música foram algumas das possibilidades relatadas, que contribuíram para a realização de propostas de ensino de música visando um equilíbrio entre proposições curriculares, realidade escolar local (limitações e possibilidades) e alunos.

Por fim, consideramos que a reformulação curricular brasileira é um assunto complexo, que exige ainda análises mais aprofundadas por parte da área de educação musical, não só a respeito dos pontos questionáveis que integram o documento, mas também em direção às adequações necessárias e estratégias que fomentem os professores de Música da Educação Básica a realizarem seus planejamentos e atividades pedagógicas, integrando as diretrizes institucionais propostas e desenvolvendo propostas de ensino 
e aprendizagem em música que sejam significativas e coerentes com cada contexto escolar. Por meio das análises, argumentações e relatos de experiências apresentados neste trabalho, esperamos contribuir para futuras discussões a respeito de parâmetros curriculares, que dialoguem com a realidade da escola pública, dos professores, alunos e comunidade que as integram.

\section{REFERÊNCIAS}

BORTOLUCCI, Ana Beatriz Forte; VALENZOLA, Juliana; COLETTI, Carla Maria Nicola. O ensino da arte na Base Nacional Comum Curricular (BNCC). Revista Eletrônica da Educação, v. 3, n. 1, p. 100-113, 2020.

BRASIL. Constituição da República Federativa do Brasil. Brasília, Senado, 1988. Disponível em: http://www.planalto.gov.br/ccivil_03/Constituicao/Constituicao.htm. Acesso em: 20 fev. 2021.

BRASIL. Estatuto da Criança e do Adolescente. Brasília: MEC, promulgado em 13 de julho de 1990.

BRASIL. Lei de Diretrizes e Bases da Educação Nacional. Lei no 9.394, Brasília: 20 de dezembro de 1996.

BRASIL. Plano Nacional de Educação. Lei n 13.005, Brasília: 25 de junho de 2014.

BRASIL. Base Nacional Comum Curricular (BNCC). Consulta Pública. Brasília, MEC/ CONSED/UNDIME. 2015. Disponível em: http://basenacionalcomum.mec.gov.br/ documento/BNCC-APRESENTACAO.pdf. Acesso em: 20 de fev. de 2021.

BRASIL. Base Nacional Comum Curricular. Proposta preliminar. $2^{a}$ versão revisada. Brasília: MEC, abril de 2016.

BRASIL. Base Nacional Comum Curricular. BNCC em Planilha. Brasília: MEC, 2018. Disponível em: basenacionalcomum.mec.gov.br. Acesso em: 30 jan. 2021.

COOPER, D. R.; SCHINDLER, P. S. Métodos de pesquisa em Administração. Porto Alegre: Bookman, 2003.

DOURADO, Luiz Fernandes; SIQUEIRA, Romilson Martins. A arte do disfarce: BNCC como gestão e regulação do currículo. Revista Brasileira de Política e Administração da Educação-Periódico científico editado pela ANPAE, v. 35, n. 2, p. 291, 2019. 
FRANÇA, Cecília Cavalieri. BNCC e educação musical: muito barulho por nada? Música na Educação Básica, v. 10, n. 12, 2020.

FRANZIM, Thiago Silva. Rádio na Escola. Relatório de Estágio Curricular Obrigatório. Curso de Licenciatura em Música. Universidade Estadual de Londrina, Londrina, 2019.

GIL, Antonio Carlos. Como elaborar projetos de pesquisa. São Paulo: Atlas, 2002.

GONTIJO, Cláudia Maria Mendes. Base nacional Comum Curricular (BNCC): comentários críticos. Revista Brasileira de Alfabetização, n. 2, 2015.

LOPES, Antonio José. BNCC: um cavalo de Tróia e/ou um tiro no pé da Educação Matemática. Anais do XII Encontro Nacional de Educação Matemática, Universidade Cruzeiro do Sul - UNICSUL, São Paulo, 2016.

LOUREIRO, Helena Ester Munari Nicolau. Metodologia de grupos multisseriais de estágio e construção da competência profissional do educador musical na licenciatura. Dissertação (Mestrado em Educação) - Universidade Estadual de Londrina, Londrina, 2006.

MACEDO, Elizabeth. Base Nacional Comum para currículos: direitos de aprendizagem e desenvolvimento para quem? Educação \& Sociedade, v. 36, n. 133, p. 891-908, 2015.

MARKONI, M. A.; LAKATOS, E. M. Técnicas de Pesquisa: Planejamento e Execução de Pesquisas, Amostragens e Técnicas de Pesquisas, Elaboração, Análise e Interpretação de Textos. 5 ed. São Paulo: Atlas, 2002.

MORENO, Jean Carlos. História na Base Nacional Comum Curricular: déjà vu e novos dilemas no século XXI. História \& Ensino, v. 22, n. 1, p. 07-27, 2016.

NEIRA, Marcos Garcia. Incoerências e inconsistências da BNCC de Educação Física. Revista Brasileira de Ciências do Esporte, v. 40, n. 3, p. 215-223, 2018.

PARANÁ. Referencial Curricular do Paraná: princípios, direitos e orientações. Curitiba, SEED, 2018. Disponível em: http://www.educadores.diaadia.pr.gov.br/arquivos/File/ bncc/2018/referencial_curricular_parana_cee.pdf. Acesso em: 20 abr. 2020.

PARANÁ.CREP - Currículo da Rede Estadual Paranaense. Curitiba, SEED, 2019a. Disponível em: http://www.educadores.diaadia.pr.gov.br/modules/conteudo/ conteudo.php?conteudo=1669. Acesso em: 20 fev. 2021. 
PARANÁ. Arte - Currículo da Rede Estadual Paranaense. Curitiba, SEED, 2019b. Disponível em: http://www.educadores.diaadia.pr.gov.br/arquivos/File/crep_2020/arte_curriculo_ rede_estadual_paranaense_20_01_2020__graf.pdf. Acesso em: 20 fev. 2021.

PARANÁ. Registro Curricular Online - RCO. Tutorial do Docente. Curitiba, SEED, 2019c. Disponível em: http://www.gestaoescolar.diaadia.pr.gov.br/modules/video/ showVideo. php?video=18731. Acesso em: 20 fev. 2021.

PARANÁ. Escola Digital Professor, 2021. Currículo da Rede Estadual Paranaense (CREP). Disponível em: http://www.escoladigital.professor.pr.gov.br/crep. Acesso em 20 mar. 2021.

PIMENTEL, Lucia Gouvêa; MAGALHÃES, Ana Del Tabor Vasconcelos. Docência em Arte no contexto da BNCC: É preciso reinventar o ensino/aprendizagem em Arte? Revista GEARTE, v. 5, n. 2, 2018.

ROMANELLI, Guilherme Gabriel Ballande. Falando sobre a arte na base nacional comum curricular-BNCC-um ponto de vista da educação musical. LinguagensRevista de Letras, Artes e Comunicação, v. 10, n. 3, p. 476-490, 2016.

SONSIN, Isabella Tais; SANCHES, Leonardo Araújo; MATOS, Ronaldo Aparecido de. Aulas de música no ensino médio: a composição como metodologia de ensino. XXIV Congresso da Associação Brasileira de Educação Musical - Educação Musical em tempos de crise: percepções, impactos e enfrentamentos. Campo Grande/MS, 2019.

SOUZA, Maria Irene Pellegrino de; CACIONE, Cleusa Erilene dos Santos. In: Curso de formação de professores de Arte - BNCC. Telêmaco Borba, 2018. 